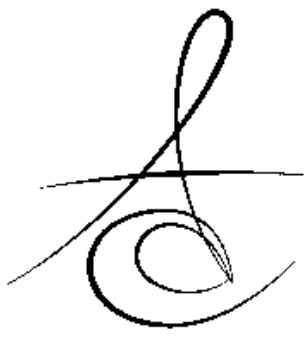

\title{
DİŞ KAVİS ŞEKİLLERİNİN VE İSTİRAHAT ARALIĞININ SPEE EĞRİSİ İLE İLIŞKİSİNİN DEĞERLENDİRİLMESİ
}

\section{EVALUATION OF THE RELATIONSHIP BETWEEN TOOTH ARC FORM AND FREEWAY-SPACE WITH SPEE CURVE}

\author{
Prof. Dr. L. İhsan ALADAĞ ${ }^{*}$
}

Arş. Gör. Dt. E.Volkan DİKEÇ*

Arş. Gör. Dt. Hilal ASUTAY*

Makale Kodu/Article code: 3032

Makale Gönderilme tarihi: 16.10 .2016

Kabul Tarihi: 07.11..2016

\section{öz}

Amaç: Bu çalışma, diş kavis şekillerinin ve istirahat aralığının spee eğrisi ile ilişkisini değerlendirmek amacıyla yapılmıştır.

Gereç ve Yöntem: Bu çalışmada Atatürk Üniversitesi Diş Hekimliği Fakültesinde eğitim görmekte olan 18-23 yaşları arasında gönüllü olan 31 erkek ve 19 bayan öğrenci seçildi. Gruplar rastgele olarak belirlendi. Tüm bireylerden alt çene ölçüsü alındı ve model elde edildi. Elde edilen modeller ark formlarına göre üçgen, kare ve oval olmak üzere üç gruba ayrıldı. Çalışmada toplam 12 farklı ölçüm yapıldı ve bu ölçümlerden 10 tanesi alçı modeller üzerinde yapılırken, 2 tanesi doğrudan bireyler üzerinde yapıldı.

Bulgular: Diş kavis şekillerinin ve istirahat aralığının spee eğrisi ile ilişkisinin anlamlı olmadığı ( $p>0.05)$ istatistiksel olarak saptandı.

Sonuçlar: Kare arka sahip bireylerde en fazla istirahat aralığı, oval arka sahip bireylerde sol tarafta en derin spee eğrisi ve üçgen arka sahip bireylerde en fazla overbite tespit edildi.

Anahtar Kelimeler: Spee eğrisi, istirahat aralığı, overbite.

\section{GİRİş}

Spee eğrisi ilk olarak 1890 yılında Ferdinand Graf Spee'nin kafataslarındaki abraze dişleri incelemesi sonucu; mandibulada kanin dişlerden ve molar dişlerin okluzal yüzeyleri boyunca devam eden kondilin ön kenarını da içine alan bir silindir şekli olarak tanımlanmıştır. Bu küre yarıçapı merkezi göz küresi olacak şekilde 6.5 ile $7.0 \mathrm{~mm}$ arasında kabul edilmektedir. Spee eğrisini sagital kesitte posterior dişlerin bukkal tüberkül tepelerinden geçen okluzyon eğrisini takip

\section{ABSTRACT}

Aim: The aim of this study was to investigate the relatıonshıp between tooth arc form and freewayspace with spee curve.

Material and Methods: Fifty (31 m/19 f, ages 18-23 years) volunteer students of Atatürk University Faculty of Dentistry were selected for this study. Groups were randomly designated. Mandibular casts were taken from all participants. Individual models of participants were divided into 3 groups. Twelve measuremens from each group were performed in the study (10 of them on models and 2 of them on participants).

Results: The participants who had square arc had higher values of spee curve $(3.22 \mathrm{~mm})$. On the other hand, the participants who had ovale arc had lowest values of spee curve $(2.94 \mathrm{~mm})$.

Conclusion: There was no significant correlation between right and left depth of spee curve values ( $p>0.05)$.

Keywords: Spee curve, freeway space, overbite

eden bir çizgi olarak düşünüldüğünde, bu eğri maksillada konveks bir şekilde, mandibulada ise konkav bir şekilde yerleşmektedir. ${ }^{1}$ Daimi dentisyonda protetik restorasyon yaparken tedavinin amacı karşılıklı koruyuculu okluzyon sağlayarak dişleri korumaktır. Spee eğrisi mandibulanın fonksiyonel eksentrik hareketleri boyunca arka dişlerin kapanışında açıklık oluşturarak dişleri korumaktadır. Ayrıca spee eğrisi arka diş tüberkül eğimleri, kondiler eğim ve insizal rehberlik ile 
birlikte istenilen okluzal düzenin oluşturulmasında önemli rol oynamaktadır. ${ }^{2}$

Dental ark, doğal dişler ve alveol kemiğinin birleşik yapısı sonucu oluşmaktadır. ${ }^{3}$ Dental arkların şekil ve büyüklüğü, ortodontik tanı ve tedavi planlamasını, dental estetiği, dişlerin stabilizasyonunu etkiler. ${ }^{4}$ Birçok dental ark çalışması genel olarak dental ark formunun başlangıç şeklinin alveoler kemiğe bağlı olarak oluştuğunu göstermiştir. ${ }^{5-7}$ Spee eğrisi ile koruyucu okluzyonun dental arkta dengeleme sağladığı rapor edilmektedir. ${ }^{8} \mathrm{Bu}$ hipotez morfolojik düzenlemenin fonksiyonel önemini ortaya koymaktadır. Yapılan diğer çalışmalar ise oklüzyon ve çiğneme sırasında oluşan kuvvetlere karşı daha iyi direnç geliştirildiği ve böylece dental arkın daha stabil olduğunu savunmaktadırlar. ${ }^{9-11}$ İstirahat dikey boyutu, kaslar ile yerçekiminin oluşturduğu, maksilla ve mandibula arasındaki postural bir ilişkidir. İstirahat dikey boyutu, mandibula fizyolojik istirahat pozisyonunda iken seçilmiş sabit iki nokta arasında ölçülen uzaklıktır.,12 İstirahat dikey boyutunu saptamak için Niswonger (2-nokta), ${ }^{13}$ en yakın konuşma mesafesi (Silverman), ${ }^{14}$ yüz profili röntgenleri ve profil fotoğrafları ${ }^{15}$ gibi birçok yöntem kullanılmaktadır. Niswonger yönteminde, orta hatta üzerinde, orta hatta burun tabanı çene ucu belirleyici nokta işaretlenir. Mandibula istirahat pozisyonunda iken bu iki nokta arasındaki mesafe ölçülür ve kaydedilir. Ardından dişler kapanıştayken bu mesafe tekrar ölçülür ve arasındaki fark istirahat aralığını verir. ${ }^{13}$ Bununla ilgili yapılan çalışmalarda; dental arkın gelişimi ve şekilleri, spee eğrisinin derinliği ve buna bağlı malokluzyonlar ve bunların yaşla ilişkileri incelenmiştir. ${ }^{16,17}$ Ancak genç erişkinlerde spee eğrisi derinliğinin sağ ve sol arkta birbirinden farkı ve bu derinliklerin dental arkın şekli ve istirahat aralığı ile bağlantısını inceleyen yeterli çalışma bulunmamaktadır. Bu çalışma ortodontik tedavi görmemiş, ağzında herhangi bir restorasyon veya diş eksikliği olmayan genç erişkinlerde, diş kavis şekillerinin ve istirahat aralığının spee eğrisi ile ilişkisini değerlendirmek amacıyla yapılmıştır. Çalışmada hipotez olarak; spee eğrisinin sağ ve sol arkta birbirine yakın olması gerektiği, ark formu üçgensel olan bireylerde kare olan bireylere oranla spee eğrisinin daha derin olması gerektiği ve spee eğrisi daha derin olanlarda istirahat aralığının daha fazla olması gerektiği belirlenmiştir.

\section{GEREÇ VE YÖNTEM}

Bu çalışmada Atatürk Üniversitesi Diş Hekimliği Fakültesinde eğitim görmekte olan 18-23 yaşları arasındaki gönüllü olan 31 erkek $(20.10 \pm 1.45)$ ve 19 bayan (20.05 \pm 1.78$)$ öğrenci seçildi. Gruplar rastgele olarak belirlendi. Gruplar belirlenirken kişilerin eksik dişi olmaması, ağzında herhangi bir restorasyon bulunmaması, ortodontik tedavi görmemiş olması ve gömülü 20 yaş dişi olmamasına dikkat edildi. ${ }^{5} \mathrm{Bu}$ çalışmada, mandibula maksillaya göre dış etkilerden daha az etkilendiği için mandibulada çalışılmıştır. ${ }^{18}$ Tüm bireylerden irreversibl hidrokolloid (Hydrogum; Zhermack $\mathrm{GmbH}$, Deutschland, Almanya) ölçü maddesi kulanılarak mandibulanın ölçüsü alındı. Ölçülerin içine tip 2 model alçısı (Elite Model; Zhermack $\mathrm{GmbH}$, Deutschland, Almanya) dökülerek model elde edildi. Elde edilen modellerden fotoğraflar alındı. Ark formları bu fotoğraflardan aydınger kağıdına aktarıldı. Bu çizimler $(x, y)$ koordinat sistemine geçirildi. Buna göre ark formları üçgen, kare ve oval olmak üzere üç gruba ayrıldı (Şekil 1).

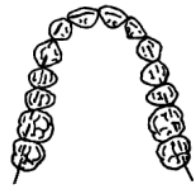

Üçgen görünümlü diş arkı

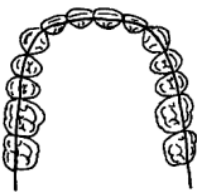

Kare görünümlü diş arkı
Şekil: 1. Diş Ark formlarının görünümü

Çalışmada toplam 12 farklı ölçüm yapıldı ve bu ölçümlerden 10 tanesi alınan ölçülerden elde edilen alçı modeller üzerinde yapılırken, 2 tanesi doğrudan bireyler üzerinde yapıldı. Belirlenen ark formlarına göre mandibula modellerinin tümünde sağ ve sol spee eğrisi derinlikleri ölçüldü. Bu ölçümler modellerde sağ ve sol arkta kanin dişlerin tüberkül tepesiyle 2. büyük azı dişlerin distobukkal tüberkül tepelerinden geçtiği varsayılan düz yüzeyden paralelometre (The J.M. Ney Company, Hartford, Connecticut, U.S.A.) kullanılarak yapıldı. Spee eğrisinin derinliği bu düz yüzeyden 1. küçük azı dişlerin

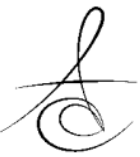


bukkal tüberküllerinin uzaklığı, 2. küçük azı dişlerin bukkal tüberküllerinin uzaklığı, 1 . büyük azı dişlerin meziobukkal tüberküllerinin uzaklığı, 1 . büyük azı dişlerinin bukkal tüberküllerinin uzaklığı ve 2 . büyük azı dişlerinin meziobukkal tüberküllerinin uzaklığı ölçülerek elde edildi (Şekil 2). Bu ölçümler 0.01 mm'ye duyarlı kumpas (Manometer Micrometer Indicator Vintage, USSR Russia) yardımıyla yapıldı. Ark formu ve cinsiyete göre bireylerin dağılımı Grafik 1'de gösterilmiştir.

Doğrudan bireyler üzerinde yapılan ölçümlerden bir tanesi istirahat aralığı boyutudur. İstirahat aralığı boyutu Niswonger yöntemiyle ölçüldü. İkinci ölçüm ise sentrik kapanışta üst santral dişlerin alt santral dişleri örtme miktarıdır. Bu ölçüm, birey dişlerini sentrik kapanışa getirdiğinde üst santral dişin insizal kenarının alt santral diş üzerinde bulunduğu nokta işaretlenerek yapıldı. Bu çizgi ile alt santral dişlerin insizal kenarı arası mesafe elektronik kumpas yardımıyla ölçüldü. Verilerin istatistiksel analizinde SPSS 20.0 programı kullanıldı. Ark formları arasındaki karşılaştırmalar için tek yönlü ANOVA, cinsiyetle ilgili verilerin analizinde bağımsız örneklemlerde $t$ testi kullanıldı. Tüm analizlerde $\mathrm{p}<0.05$ istatistiksel olarak anlamlı kabul edilmiştir.

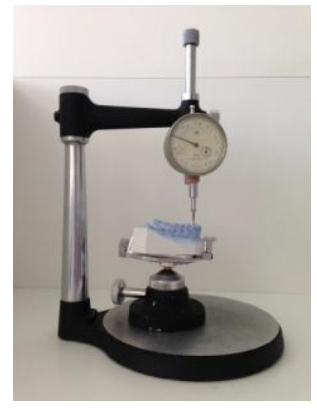

Şekil 2. Alt çenede spee eğrisi derinliklerinin paralalometre ile

\section{BULGULAR}

Çalışmaya dahil olan bireylerin 16'sında kare

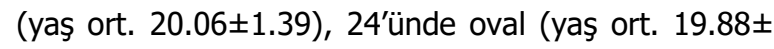

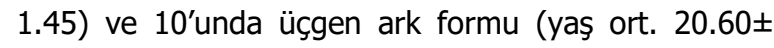
2.07) bulunmaktadır (Tablo 1). İstirahat aralığı ortalamalarına bakıldığında en yüksek değer, kare arka sahip bireylerde (3.22 mm) en düşük değer ise oval arka sahip bireylerde $(2.94 \mathrm{~mm})$ tespit edildi. Overbite ortalamalarına bakıldığında ise en yüksek değer üçgen arka sahip bireylerde $(4.27 \mathrm{~mm})$ en düşük değer ise oval arka sahip bireylerde (3.54 mm) görüldü (Tablo 2). Elde edilen alçı modeller üzerinde yapılan ölçümlere ait veriler Tablo 3'te gösterildi. Bu tabloya göre; Alt 1. küçük azı dişi bukkal tüberkülünün okluzal düzleme olan uzaklık ortalamaları ark şekillerine göre karşılaştırıldığında; en yüksek değer $(0.79 \mathrm{~mm})$ oval ve üçgen arka sahip bireylerde sol tarafta, en düşük değer ise $(0.47 \mathrm{~mm})$ kare arka sahip bireylerde sağ tarafta bulundu. Alt 2. Küçük azı dişi bukkal tüberkülünün okluzal düzleme olan uzaklık ortalamaları ark şekillerine göre karşılaştırıldığında; en yüksek değer (1.39 mm) oval arka sahip bireylerde sol tarafta, en düşük değer ise $(0.90 \mathrm{~mm})$ kare arka sahip bireylerde sağ tarafta bulundu. Alt 1 . büyük azı dişi mezio-bukkal tüberkülünün okluzal düzleme olan uzaklık ortalamaları ark şekillerine göre karşılaştırıldığında; en yüksek değer $(1.71 \mathrm{~mm})$ oval arka sahip bireylerde sol tarafta, en düşük değer ise $(1.33 \mathrm{~mm})$ kare arka sahip bireylerde sağ tarafta bulundu. Alt 1 . büyük azı dişi bukkal tüberkülünün okluzal düzleme olan uzaklık ortalamaları ark şekillerine göre karşılaştırıldığında; en yüksek değer $(1.46 \mathrm{~mm})$ oval arka sahip bireylerde sol tarafta, en düşük değer ise $(1.10 \mathrm{~mm})$ kare arka sahip bireylerde sağ tarafta bulunmuştur. Alt 2. büyük azı dişi meziobukkal tüberkülünün okluzal düzleme olan uzaklık ortalamaları ark şekillerine göre karşılaştırıldığında; en yüksek değer (0.78 mm) oval arka sahip bireylerde sol tarafta, en düşük değer ise $(0.60 \mathrm{~mm})$ kare arka sahip bireylerde sağ tarafta bulunmuştur. Ark şekillerine göre istatistiksel değerlendirmeler Tablo 4 'te verilmiştir. Bu değerlendirmeye göre; ark formuna göre gruplar arasında istirahat aralığı ölçümlerinde istatiksel olarak anlamlı farklılık bulunmamıştır ( $p>0.05$ ). Aynı zamanda ark formuna göre gruplar arasında overbite ölçümlerinde de istatiksel olarak anlamlı bir farklılık bulunmamıştır ( $p>0.05)$. Ark şekillerine göre karşılaştırmalarda, gruplar arasında 1. küçük azı bukkal tüberkülü, 2. küçük azı bukkal tüberkülü, 1. büyük azı meziobukkal tüberkülü, 1 . büyük azı bukkal tüberkülü ve 2. büyük azı meziobukkal tüberkülü ölçümlerinde istatiksel olarak anlamlı farklılık bulunmamıştır.( $p>0.05)$ Bireylerde sağ ve sol yarım çenede yapılan ölçümler kendi aralarında değerlendirildiğinde; 1. küçük azı bukkal tüberkülü, 2. küçük azı bukkal tüberkülü, 1 . büyük azı meziobukkal tüberkülü, 1 . büyük azı bukkal tüberkülü ve 2. büyük azı meziobukkal tüberkülü ölçümlerinde istatiksel olarak anlamlı farklılık bulunmamıştır ( $p>0.05$ ) (Tablo 5). 
Tablo 1. Bireylerin ark formları ve yaş ortalamaları.

\begin{tabular}{|c|c|c|c|c|c|c|}
\hline \multirow{4}{*}{ Ark Formu } & $\mathrm{N}$ & $\begin{array}{c}\text { Ortalama } \\
(\mathrm{mm})\end{array}$ & $\begin{array}{c}\text { Standart } \\
\text { Sapma }\end{array}$ & $\begin{array}{c}\text { Minimum } \\
(\mathrm{mm})\end{array}$ & $\begin{array}{c}\text { Maksimum } \\
(\mathrm{mm})\end{array}$ \\
\hline YAS & Kare & 16 & 20.06 & 1,39 & 18 & 23 \\
\cline { 2 - 7 } & Oval & 24 & 19.88 & 1.45 & 18 & 23 \\
\cline { 2 - 7 } & Ücgen & 10 & 20.60 & 2.07 & 18 & 23 \\
\cline { 2 - 7 } & Toplam & 50 & 20.08 & 1.56 & 18 & 23 \\
\hline
\end{tabular}

Tablo 2. İstirahat dikey boyutu, overbite ve ark formları.

\begin{tabular}{|l|l|c|c|c|c|c|}
\hline & Ark Formu & $\mathrm{N}$ & $\begin{array}{c}\text { Ortalama } \\
(\mathrm{mm})\end{array}$ & $\begin{array}{c}\text { Standart } \\
\text { Sapma }\end{array}$ & $\begin{array}{c}\text { Minimum } \\
(\mathrm{mm})\end{array}$ & $\begin{array}{c}\text { Maksimum } \\
(\mathrm{mm})\end{array}$ \\
\hline İstirahat \\
$\begin{array}{l}\text { Dikey } \\
\text { Boyutu }\end{array}$ & Kare & 16 & 16 & 3.22 & .94 & 1.98 \\
\cline { 2 - 7 } & Oval & 24 & 24 & 2.94 & .95 & 1.38 \\
\cline { 2 - 7 } & Ücgen & 10 & 10 & 3.08 & .96 & 1.93 \\
\cline { 2 - 7 } & Toplam & 50 & 50 & 3.06 & .94 & 1.38 \\
\hline \multirow{5}{*}{ Overbite } & Kare & 16 & 3.57 & 1.45 & .00 & 5.98 \\
\cline { 2 - 7 } & Oval & 24 & 3.54 & 1.78 & .00 & 6.18 \\
\cline { 2 - 7 } & Ǘgen & 10 & 4.27 & 1.06 & 2.48 & 5.85 \\
\cline { 2 - 7 } & Toplam & 50 & 3.70 & 1.56 & .00 & 6.18 \\
\hline
\end{tabular}

Tablo 3. Dişlerin sağ ve sol spee eğrisi derinliği ölçümleri.

\begin{tabular}{|c|c|c|c|c|c|c|c|c|c|c|c|}
\hline & Ark Formi & \begin{tabular}{|l|l|}
$\mathrm{N}$ & Ort. $(\mathrm{mm})$ \\
\end{tabular} & Standart Sapm & \begin{tabular}{l|l} 
ain. $(\mathrm{mm})$ \\
\end{tabular} & Maks. (mm) & & Ark Formu & \begin{tabular}{|l|l|}
$\mathrm{N}$ & Ort. $(\mathrm{mm}$ \\
\end{tabular} & Standart Sapma & Min. $(\mathrm{mm})$ & Maks. $(\mathrm{mm})$ \\
\hline & Kare & \begin{tabular}{|l|l|}
16 & .47 \\
\end{tabular} & .54 & -.23 & 1.88 & \multirow[t]{4}{*}{$\tilde{0}$} & Kare & \begin{tabular}{|l|l|}
16.53 \\
\end{tabular} & .59 & -.60 & 1.48 \\
\hline ֶֶ, & Oval & \begin{tabular}{|l|l|}
24.78 \\
\end{tabular} & .61 & -.16 & 2.30 & & Oval & \begin{tabular}{|l|l|}
24.79 \\
\end{tabular} & .58 & -.37 & 2.01 \\
\hline & Üccgen & \begin{tabular}{|l|l|}
10.70 \\
\end{tabular} & .41 & .07 & 1.15 & & Ücgen & \begin{tabular}{|l|l|}
10.79 \\
\end{tabular} & .52 & .10 & 1.61 \\
\hline & Total & \begin{tabular}{|l|l|}
50 & .67 \\
\end{tabular} & .56 & -.23 & 2.30 & & Total & \begin{tabular}{|l|l|}
50 & .71 \\
\end{tabular} & .57 & -.60 & 2.01 \\
\hline & Kare & \begin{tabular}{|l|l|}
16 & .90 \\
\end{tabular} & .63 & -.59 & 1.71 & \multirow[t]{4}{*}{ ñ } & Kare & \begin{tabular}{|l|l|}
16 & .97 \\
\end{tabular} & .51 & -.24 & 1.59 \\
\hline صึّ، & Oval & \begin{tabular}{|l|l|}
24 & 1.17 \\
\end{tabular} & .78 & -.27 & 2.42 & & Oval & \begin{tabular}{|l|l|}
24 & 1.39 \\
\end{tabular} & .82 & -.04 & 2.80 \\
\hline & Ǘcgen & \begin{tabular}{|l|l|}
10 & 1.00 \\
\end{tabular} & .32 & .55 & 1.50 & & Ǘcgen & \begin{tabular}{|l|l|}
10 & 1.09 \\
\end{tabular} & .48 & .22 & 1.92 \\
\hline & \begin{tabular}{|l|} 
Total \\
\end{tabular} & \begin{tabular}{|l|l|}
50 & 1.05 \\
\end{tabular} & .66 & \begin{tabular}{|l|}
-.59 \\
\end{tabular} & 2.42 & & Total & \begin{tabular}{|l|l|}
50 & 1.20 \\
\end{tabular} & .69 & -.24 & 2.80 \\
\hline & Kare & \begin{tabular}{|l|l|}
16 & 1.33 \\
\end{tabular} & .60 & .14 & 2.30 & \multirow{4}{*}{ ֶֻ } & Kare & \begin{tabular}{|l|l|}
16 & 1.51 \\
\end{tabular} & .56 & .56 & 2.39 \\
\hline ֶֶ, & Oval & \begin{tabular}{|l|l|}
24 & 1.60 \\
\end{tabular} & .75 & .19 & 2.67 & & Oval & \begin{tabular}{|l|l|}
24 & 1.71 \\
\end{tabular} & .86 & .00 & 3.25 \\
\hline & Ücçen & \begin{tabular}{|l|l|}
10 & 1.51 \\
\end{tabular} & .43 & .66 & 2.01 & & Ücçen & \begin{tabular}{|l|l|}
10 & 1.46 \\
\end{tabular} & .51 & .55 & 2.03 \\
\hline & \begin{tabular}{|l|} 
Total \\
\end{tabular} & \begin{tabular}{|l|l|}
50 & 1.50 \\
\end{tabular} & .65 & .14 & 2.67 & & Total & \begin{tabular}{|l|l|}
50 & 1.59 \\
\end{tabular} & .71 & .00 & 3.25 \\
\hline & Kare & \begin{tabular}{|l|l|}
16 & 1.10 \\
\end{tabular} & .63 & -.39 & 2.13 & \multirow{4}{*}{ 으 } & Kare & \begin{tabular}{|l|l|}
16 & 1.27 \\
\end{tabular} & .50 & .31 & 2.00 \\
\hline ֶ̆, & Oval & \begin{tabular}{|l|l|}
24 & 1.31 \\
\end{tabular} & .68 & .04 & 2.53 & & Oval & \begin{tabular}{|l|l|}
24 & 1.46 \\
\end{tabular} & .73 & -.18 & 2.47 \\
\hline & Ü̈çaen & \begin{tabular}{|l|l|}
10 & 1.31 \\
\end{tabular} & .46 & .33 & 1.95 & & \begin{tabular}{|l|l|l|l} 
Ücgen \\
\end{tabular} & \begin{tabular}{|l|l|}
10 & 1.24 \\
\end{tabular} & .46 & .45 & 1.86 \\
\hline & \begin{tabular}{|l|} 
Total \\
\end{tabular} & \begin{tabular}{|l|l}
50 & 1.24 \\
\end{tabular} & .62 & -.39 & 2.53 & & Total & \begin{tabular}{|l|l}
50 & 1.36 \\
\end{tabular} & .61 & -.18 & 2.47 \\
\hline & Kare & \begin{tabular}{|l|l|}
16 & 60 \\
\end{tabular} & 33 & .09 & 1.33 & \multirow{4}{*}{$\underline{\tilde{O}}$} & Kare & \begin{tabular}{|l|l|}
16 & 73 \\
\end{tabular} & .41 & .07 & 1.51 \\
\hline N & Oval & \begin{tabular}{|l|l}
24.72 \\
\end{tabular} & .41 & .06 & 2.09 & & Oval & \begin{tabular}{|l|l}
24.78 \\
\end{tabular} & .33 & .26 & 1.46 \\
\hline & Ücaen & \begin{tabular}{|l|l}
10.66 \\
\end{tabular} & .30 & .13 & 1.13 & & Üccaen & \begin{tabular}{|l|l}
10.71 \\
\end{tabular} & .32 & .42 & 1.55 \\
\hline & \begin{tabular}{|l|} 
Total \\
\end{tabular} & \begin{tabular}{|l|l}
50 & .67 \\
\end{tabular} & .36 & .06 & 2.09 & & Total & \begin{tabular}{|l|l}
50 & .75 \\
\end{tabular} & .35 & .07 & 1.55 \\
\hline
\end{tabular}

Tablo 4: Ark şekillerine göre istatistiksel değerlendirmeler

\begin{tabular}{|l|c|c|c|c|c|}
\hline & $\begin{array}{c}\text { Karelerin } \\
\text { toplamı }\end{array}$ & Df & $\begin{array}{c}\text { Ortalamaların } \\
\text { karesi }\end{array}$ & $\mathrm{F}$ & $\mathrm{P}$ \\
\hline İstirahat dikey b oyutu & .731 & 2 & .365 & .404 & .670 \\
\hline Overbite & 4.193 & 2 & 2.097 & .859 & .430 \\
\hline Sağ 1.küçük azı & .921 & 2 & .461 & 1.491 & .236 \\
\hline Sağ 2.küçük azı & .754 & 2 & .377 & .856 & .431 \\
\hline $\begin{array}{l}\text { Sağ 1.büyük azı mezio- } \\
\text { bukkal }\end{array}$ & .736 & 2 & .368 & .867 & .427 \\
\hline Sağ 1.büyük azı bukkal & .473 & 2 & .237 & .605 & .550 \\
\hline $\begin{array}{l}\text { Sağ 2.büyük azı mezio- } \\
\text { bukkal }\end{array}$ & .150 & 2 & .075 & .563 & .573 \\
\hline Sol 1.küçük azı & .759 & 2 & .379 & 1.163 & .321 \\
\hline Sol 2.küçük azı & 1.853 & 2 & .927 & 2.044 & .141 \\
\hline $\begin{array}{l}\text { Sol 1.büyük azı ezio- } \\
\text { bukkal }\end{array}$ & .620 & 2 & .310 & .611 & .547 \\
\hline Sol 1.büyük azı ukkal & .529 & 2 & .264 & .703 & .500 \\
\hline $\begin{array}{l}\text { Sol 2.büyük azı mezio- } \\
\text { bukkal }\end{array}$ & .056 & 2 & .028 & .221 & .802 \\
\hline
\end{tabular}

Tablo 5. Spee eğrisi sağ ve sol yarım çene ölçümlerinin istatistiksel değerlendirmeleri.

\begin{tabular}{|l|l|l|l|}
\hline & Ortalama $(\mathrm{mm})$ & Standart Sapma & $\mathrm{P}$ \\
\hline Sağ 4 - Sol 4 & -.04320 & .50578 & .549 \\
\hline Sağ 5 - Sol 5 & -.14620 & .56818 & .075 \\
\hline $\begin{array}{l}\text { Sağ 6 mezial - Sol } \\
\text { 6 mezial }\end{array}$ & -.09720 & .45371 & .136 \\
\hline Sağ 6 distal & -.11520 & .44772 & .075 \\
\hline Sağ 7 mezial & -.08180 & 35009 & 105 \\
\hline
\end{tabular}

\section{TARTIŞMA}

Bu çalışmanın sonuçlarına göre: istirahat aralığı ölçümleri en yüksek kare arka sahip bireylerde, en düşük ise oval arka sahip bireylerde görülmüştür. Overbite ölçümleri ise en yüksek üçgen arka sahip bireylerde en düşük ise oval arka sahip bireylerde görülmüştür. Spee eğrisi en derin oval arka sahip bireylerde sol bölgede, en sığ ise kare arka sahip bireylerde sağ bölgede görülmüştür. Ancak bu değerler arasında istatistiksel olarak anlamlı bir fark

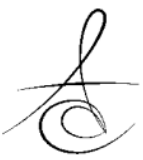


görülmemiştir ( $p>0.05)$. Mohan ve ark. ${ }^{19}$ yaptıkları çalışmada iki farklı yaş grubunda (18-25 ve $35-44)$ spee eğrisinin derinliğini değerlendirmişler ve spee eğrisinin yaşa bağı olarak anlamlı bir şekilde artmadığını göstermişlerdir. Marshall ve ark. ${ }^{16}$ spee eğrisinin gelişimiyle ilgili yaptıkları çalışmada 33 hastada 4 yaşından 26 yaşına kadar spee eğrisinin derinliğini ölçmüşlerdir. Bu çalışmanın sonucuna göre; spee eğrisi başlangıçta alt daimi birinci molar ve kesicilerin sürmesi sonucu oluşmakta ve alt daimi ikinci azı dişleri sürdüğü zaman derinleşmektedir. Daimi dişlenme dönemi tamamlandığı zaman eğri derinliğinin biraz azaldığı ve daha sonra erken yetişkinlikte de hemen hemen sabit kaldığı bildirilmiştir. Ferrario ve ark. ${ }^{5}$ yaptıkları çalışmada dental ark formunun yaştan ve cinsiyetten etkilenmediğini bildirmişlerdir. Yukarıdaki çalışmaların sonuçları doğrultusunda bu çalışmada spee eğrisi derinliği $18-23$ yaş arası yetişkin bireylerden ölçülmüştür. Forster ve ark. ${ }^{20}$ yaptıkları çalışmada cinsiyete göre dental ark genişliğiyle dikey yüz yüksekliği arasındaki ilişkiyi karşılaştırmışlardır. Ark genişliğinin erkeklerde kadınlardan daha fazla olduğunu bildirmişlerdir. Bununla birlikte dikey yüz yüksekliği arttıkça dental ark genişliğinin azaldığı görülmüştür. Grippaudo ve ark. ${ }^{18}$ yaptıkları çalışmada dental ark formuyla dikey yüz formunun birbirleriyle ilişkisini araş̧ırmışlar üst dental ark formu ile dikey yüz şekli arasında ilişki olduğunu göstermişlerdir. Bu çalışmada ise istirahat dikey boyutu ölçümleri en yüksek kare arka sahip bireylerde en düşük ise oval arka sahip bireylerde görülmüş, ancak dental ark formu ile istirahat dikey boyutu arasında anlamlı bir ilişki bulunamamışı ı $(p>0.05)$. Rapor edilen farkı sonuçların sebebi çalışılan yaş gruplarının farklı olması olarak düşünülmektedir. Pandis ve ark. ${ }^{21}$ yaptıkları çalışmada spee eğrisinin seviyesinin mandibular ark genişliğine etkilerini incelemişlerdir. Farkı seviyede spee eğrisi ile ark genişliği arasında anlamlı bir fark olmadığını göstermişlerdir. Cheon ve ark. ${ }^{22}$ Koreli yetişkinlerde spee eğrisi ve dentofasiyal morfoloji arasındaki ilişkiyi incelemişlerdir. Spee eğrisi derinlik miktarının, kişideki overbite ve overjet miktarı ile ilgili olduğunu bildirmişlerdir. Bununla birlikte cinsiyetin spee eğrisi üzerinde etkili olmadığı sonucunu çıkarmışlardır. Ghezzi ve ark. ${ }^{23}$ yaptıkları çalışmada spee eğrisi derinliği ile dikey yüz yüksekliğini gösteren parametreler arasında anlamlı bir farkllık gözlenmediğini bildirmişlerdir. Sabah ve Oncag $^{24} 90$ hastada yaptıkları çalışmada, spee eğrisi derinliği ile dikey boyutla ilgili parametreler arasındaki ilişkiyi incelemişler ve parametreler arasında anlamlı bir ilişki olmadığını gözlemlemişlerdir. Bu çalışmada da spee eğrisinin derinliği ile istirahat aralığı arasında anlamlı bir ilişki bulunamamıştır $(p>0.05)$. Bielawska ${ }^{25}$ yaptıkları çalışmada büyüme ve gelişmeye bağlı dental ark genişliğinin kesiciler arasındaki overbite miktarından etkilenebileceğini bildirmişlerdir. Bu çalışmada ise sadece kişiler arasındaki ark formu ile overbite ilişkisi incelenmiştir. Bu inceleme sonucunda ark formu ve overbite arasında anlamlı bir fark bulunamamıştır $(p>0.05)$.

\section{SONUÇLAR}

- İstirahat aralığı en fazla kare arka sahip bireylerde, sonra üçgen arka sahip bireylerde, en az oval arka sahip bireylerde görülmüştür.

- Spee eğrisi oval arka sahip bireylerde sol tarafta en derin, kare arka sahip bireylerde sağ tarafta en sığ olarak saptanmışır.

- Overbite en fazla üçgen arka sahip bireylerde, sonra kare arka sahip bireylerde, en az oval arka sahip bireylerde tespit edilmiştir.

\section{L.İhsan Aladağ ORCID ID: 0000-0001-7380-1472 \\ E. Volkan Dikeç ORCID ID: 000-0002-1069-1381 \\ Hilal Asutay, ORCID ID: 000-0002-2805-5500}

\section{KAYNAKLAR}

1. The gliding path of the mandible along the skull. Ferdinand Graf Spee (1855-1937), prosector at the Anatomy Institute of Kiel. J Am Dent Assoc 1980; 100: 670-5.

2. Okeson J. Management of temporomandibular disorders and occlusion. 5th Baskı. St Louis:, Mosby, 2003: p. 67-197.

3. Prosthodontics. TAo. The Glossary of Prosthodontic Terms. Baskı. 2005: p. 30-80.

4. Brash J. The etiology of irregularity and malocclusion of the teeth. 2nd Baskı. London, Dental Board of the United Kingdom, 1956.

5. Ferrario VF, Sforza C, Poggio CE, Serrao G, Colombo A. Three-dimensional dental arch curvature in human adolescents and adults. Am J Orthod Dentofacial Orthop 1999; 115: 401-5. 
6. Paranhos LR, Lima CS, da Silva RH, Daruge Junior $\mathrm{E}$, Torres FC. Correlation between maxillary central incisor crown morphology and mandibular dental arch form in normal occlusion subjects. Braz Dent J 2012; 23: 149-53.

7. Ronay V, Miner RM, Will LA, Arai K. Mandibular arch form: the relationship between dental and basal anatomy. Am J Orthod Dentofacial Orthop 2008; 134: 430-8.

8. Enlow D. Normal variations in facial form and the anatomic basis for malocclusion. İçinde:Enlow D (editör). Facial growth,, 3rd Baskı. Philadelphia: WB Saunders Co, 1990: p. 193-221.

9. Osborn JW. Helicoidal plane of dental occlusion. Am J Phys Anthropol 1982; 57: 273-81. 10. Osborn JW. Orientation of the masseter muscle and the curve of Spee in relation to crushing forces on the molar teeth of primates. Am J Phys Anthropol 1993; 92: 99-106.

11. Ash M. Wheeler' dental anatomy, physiology and occlusion. Baskı. Philadelphia: WB Saunders Co, 1993.

12. Güldağ MÜ, Yanıkoğlu N, Ceylan G, Bayındır F. Oklüzal dikey boyutun belirlenmesi doğal dişli bireylerde sentrik oklüzyon durumundaki alt ve üst anterior dişlerin ölçümlerinden yararlanılması. Atatürk Univ Diş Hek Fak Derg 1997; 7: 17-21.

13. Joniot B. [Physiologic rest position of the mandible]. Dent Labor (Munch) 1974; 22: 786-8.

14. Silverman MM. The speaking method in measuring vertical dimension. J Prosthet Dent 2001; 85: 42731.

15. Orsini MG, Huang GJ, Kiyak HA, Ramsay DS, Bollen AM, Anderson NK, Giddon DB. Methods to evaluate profile preferences for the anteroposterior position of the mandible. Am J Orthod Dentofacial Orthop 2006; 130: 283-91.

16. Marshall $S D$, Caspersen $M$, Hardinger $R R$, Franciscus RG, Aquilino SA, Southard TE. Development of the curve of Spee. Am J Orthod Dentofacial Orthop 2008; 134: 344-52.

17. Volpato B, Di Carlo S, Shahinas J, Mencio F, Fusco $\mathrm{R}$, Pompa G. Investigation of complete dental arches of 23 patients aged at least 75 years. Ann Stomatol (Roma), 2011; 2: 19-24.

18. Grippaudo C, Oliva B, Greco AL, Sferra S, Deli R. Relationship between vertical facial patterns and dental arch form in class II malocclusion. Prog Orthod 2013; 14: 43.

19. Mohan M, D'Souza M, Kamath G, Parolia A. Comparative evaluation of the curve of Spee in two age groups and its relation to posterior teeth disclusion. Indian J Dent Res 2011; 22: 179.

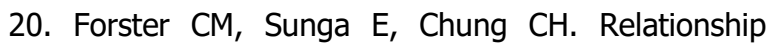
between dental arch width and vertical facial morphology in untreated adults. Eur J Orthod 2008; 30: 288-94.

21. Pandis N, Polychronopoulou A, Sifakakis I, Makou $M$, Eliades $T$. Effects of levelling of the curve of Spee on the proclination of mandibular incisors and expansion of dental arches: a prospective clinical trial. Aust Orthod J 2010; 26: 61-5.

22. Cheon SH, Park YH, Paik KS, Ahn SJ, Hayashi K, Yi WJ, Lee SP. Relationship between the curve of Spee and dentofacial morphology evaluated with a 3-dimensional reconstruction method in Korean adults. Am J Orthod Dentofacial Orthop 2008; 133: 640 e7-14.

23. Ghezzi F, Drago E, De Thomatis $P$, Zallio F. [Depth of the curve of Spee in relation to FMA, FH, ANB and dental class]. Mondo Ortod 1991; 16: 73-6.

24. Sabah M, Oncag G. Spee egrisinin derinliginin Angle sınıflandırılması ve dik yön gelişimine baglı değişimi. Turk Ortodonti Dergisi 2002; 15: 163165.

25. Bielawska H. [Treatment using the Lehman apparatus in patients with malocclusion in light of teleradiologic tests and dental arch measurements]. Ann Acad Med Stetin 2002; 48: 195-212.

\author{
Yazışma Adresi \\ Dr. Engin Volkan Dikeç, \\ Atatürk Üniversitesi \\ Diş Hekimliği Fakültesi \\ Protetik Diş Tedavisi AD. \\ ERZURUM \\ Tel: +05558481537 \\ e-mail: alluih@atauni.edu.tr
}

